\title{
Novel Characteristics of Subsonic Coflowing Jets With Varying Lip Thickness
}

\author{
Naren Shankar Radha Krishnan¹, Dilip Raja Narayana2,*
}

How to cite

R. K. Naren Shankar (D https://orcid.org/0000-0002-3363-4478 N. Dilip Raja (D) https://orcid.org/0000-0001-9825-6503

R. K. Naren Shankar and N. Dilip Raja (2020) Novel

\begin{abstract}
Characteristics of Subsonic Coflowing Jets With Varying Lip Thickness. J Aerosp Technol Manag, 18: e2520 https://doi. org/10.5028/jatm.v12.1122
\end{abstract}

\begin{abstract}
Effect of Mach number on coflowing jet at lip thickness of $0.2 D_{p}, 1.0 D_{p}$ and $1.5 D_{p}$ (where $D_{p}$ is primary nozzle exit diameter, $10 \mathrm{~mm}$ ) at Mach numbers 1.0, 0.8 and 0.6 were studied experimentally. It was found that an increase in Mach number does not have any profound effect on axial total and static pressure variation for $0.2 D_{p}$. Decreasing the mean diameter is due to the geometrical constraints. In this study, the primary nozzle dimension and secondary duct is maintained constant for comparison. For the case of $0.2 D_{p}$, static pressure is almost equal to atmospheric pressure for all Mach numbers. Whereas for other two lip thickness, increase in Mach number marginally influences axial total pressure and profoundly varies static pressure. It is noted that it varies considerably up to $11.1 \%$ in the axial direction and up to $17 \%$ in the radial direction for Mach number 1.0. For lower Mach numbers, such variation is not observed. Increase in Mach number increases static pressure variation in the coflowing jet flow field with lip thickness $1.0 D_{p}$ and $1.5 D_{p}$.
\end{abstract}

KEYWORDS: Coflowing jet; Lip thickness; Static pressure; Subsonic jet; Mixing enhancement; Mixing inhibition.

\section{INTRODUCTION}

Mixing in coflowing jet (CFJ) suppresses noise and reduces infrared (IR) signature in commercial aircraft turbofan engines. To reduce IR signature, jet potential core volume and surface area should be reduced. Modification of coflowing nozzle can alter mixing in CFJ (Zaman and Papamoschou 2000; Papamoschou 2000; Shupe 2007). Such modifications do not require additional power source and that are called as passive control in CFJ.

Some of the factors that are associated with CFJ include: lip thickness (LT), wake dominance, angular jet and mixing enhancement. Lip thickness (LP) is the distance separating primary nozzle and secondary duct. For low subsonic jets, it is well proven that increase in lip thickness enhances mixing because of wake dominance (Buresti et al. 1994).

Figure 1 shows the sketch of the coflowing jet profile. It reveals various regions within the jet recirculation zone become dominant under the influence of lip thickness and bypass ratio. Wake dominance creates a recirculation zone that deflects the secondary jet towards primary jet. This increases interaction between the jets and enhances mixing. For high subsonic jets, only few researchers have performed the effect of lip thickness with varying Mach number. When coflow exist at an angle to the horizontal with respect to CFJ, it is called angular coflow. The secondary jets in CFJ that flow at an inclination to the primary jets are called as angular jet.

Papamoschou (2000) studied the effect of secondary jet on primary jet on high subsonic and supersonic Mach numbers mixing enhances with high velocity secondary jet, particularly supersonic. A similar work with coannular nozzle was reported by Zaman

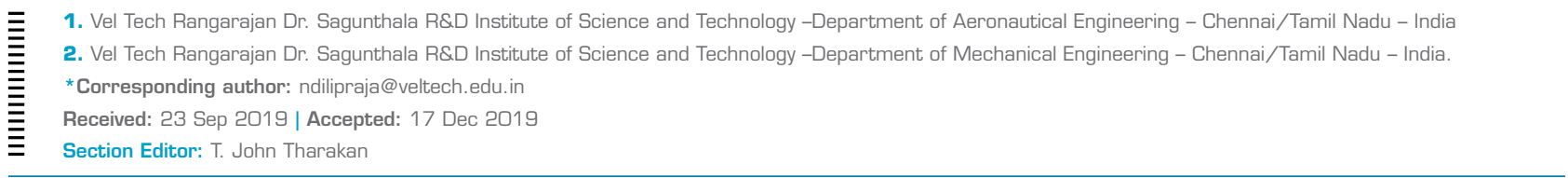


and Papamoschou (2000). The mixing enhanced in the surrounding jet around exit Mach number of 0.8 to 1.2 , irrespective of the operating conditions of the central jet. A scaled down version of typical turbo fan exhaust has been studied with varying secondary nozzle area (Shupe et al. 2007). They made secondary nozzle as converging-diverging and varied the secondary nozzle exit area to the throat area ratio from 1.0 to 1.6. Centerline velocity survey was taken for exit Mach number 0.6 to 1.0 in the primary jet. It was concluded that the effect of varying Mach number of the primary jet is relatively minor, whereas core of primary jet is practically eliminated for the secondary nozzle area ratio above 1.4 .

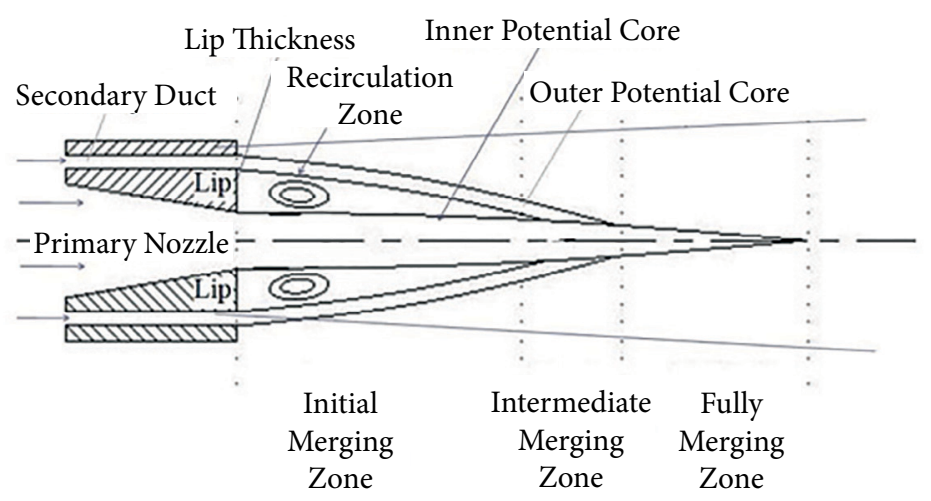

Figure 1. Profile of coflowing jet with finite lip thickness (Shankar 2017).

In all the above cases the primary nozzle lip thickness was maintained as $0.7 \mathrm{~mm}$ and mixing enhancement is achieved only by varying the secondary jet Mach number. Lovaraju and Rathakrishnan (2011) studied the effect of Mach number in CFJ below sonic, correctly expanded sonic and under expanded sonic up to nozzle pressure ratio (NPR) (nozzle exit pressure against back pressure) of NPR 7. They concluded that mixing inhibits with upsurge in primary jet Mach number. At this stage it is worth noting that, increase in LT from 0.7 to $2.65 \mathrm{~mm}$ influences the mixing behavior of CFJ. The potential core length of primary jet elongates in the presence of secondary jet. Srinivasarao et al. (2013) analyzed CFJ from orifices with lip thickness 1.5 and $4.5 \mathrm{~mm}$. CFJ with $4.5 \mathrm{~mm}$ lip enhanced mixing and the effect of Mach number is found marginal. Similar study on CFJ nozzles with LT 3 and $15 \mathrm{~mm}$ was performed for a constant Mach number of 0.6 and NPR 7. But they did not study the effect of varying Mach number in such finite range of lip thicknesses. Few studies were performed by (Shankar et al. 2016; 2017; 2018; 2019; Thanigaiarasu et al. 2018) on the effect of bypass ratio and lip thickness on CFJ. But specific emphasis was not given for the effect of increasing Mach number in CFJ on range of lip thickness. The present study caters the gap in literature. The current work studies the effect of Mach number on characteristics of typical coflowing jet that has varying lip thickness.

\section{EXPERIMENTAL}

Experiments were carried out at the High-speed Jet Laboratory, KCG College of Technology, Chennai, India. In this current study, the primary and the secondary jets have a single feed system and hence the Mach number of the secondary jet is not controlled. Due to friction, the secondary jet encounters losses that are tabulated in Table 1.

In all the cases of the present study, exit dimensions for primary and secondary jet are maintained constant. The exit diameter primary nozzle $\left(\mathrm{D}_{\mathrm{p}}\right)$ is $10 \mathrm{~mm}$ and the width of secondary duct is $5 \mathrm{~mm}$. Three LTs of $2 \mathrm{~mm}(0.2 \mathrm{D}$ p), $10 \mathrm{~mm}$ $\left(1.0 \mathrm{D}_{\mathrm{p}}\right)$ and $15 \mathrm{~mm}\left(1.5 \mathrm{D}_{\mathrm{p}}\right)$ were analyzed for primary jet exit Mach numbers 0.6, 0.8 and 1.0 with NPR $1.28,1.52$ and 1.89 respectively. The designs of coflowing nozzles are shown in Figs. 2, 3 and 4. Free jet facility is used to carry out the experiments as shown in Fig. 5. 
Table 1. Experimental conditions at CFJ Nozzle exit.

\begin{tabular}{|c|c|c|c|c|c|c|}
\hline CFJ & $\begin{array}{l}P_{\text {os }} / P_{\text {op }} \\
{[\%]}\end{array}$ & $\begin{array}{l}P_{\mathrm{Op}} \\
{[\mathrm{atm}]}\end{array}$ & $\underset{[\mathrm{atm}]}{\mathbf{P}_{\mathrm{Os}}}$ & $\mathrm{M}_{\mathrm{p}}$ & $M_{s}$ & $\begin{array}{l}\text { Percentage loss in secondary jet } \\
{[\%]}\end{array}$ \\
\hline \multirow{3}{*}{ LT $0.2 \mathrm{D}_{\mathrm{p}}$} & 90.0 & 1.276 & 1.248 & 0.6 & 0.57 & 2.2 \\
\hline & 90.0 & 1.524 & 1.472 & 0.8 & 0.76 & 3.4 \\
\hline & 90.0 & 1.893 & 1.804 & 1.0 & 0.95 & 4.7 \\
\hline \multirow{3}{*}{ LT $1.0 \mathrm{D}_{\mathrm{p}}$} & 82.5 & 1.276 & 1.227 & 0.6 & 0.55 & 3.8 \\
\hline & 84.3 & 1.524 & 1.442 & 0.8 & 0.74 & 5.4 \\
\hline & 86.0 & 1.893 & 1.768 & 1.0 & 0.94 & 6.6 \\
\hline \multirow{3}{*}{ LT $1.5 \mathrm{D}_{\mathrm{p}}$} & 42.1 & 1.276 & 1.162 & 0.6 & 0.40 & 13.8 \\
\hline & 54.0 & 1.524 & 1.283 & 0.8 & 0.61 & 14.7 \\
\hline & 72.2 & 1.893 & 1.645 & 1.0 & 0.87 & 15.5 \\
\hline
\end{tabular}

Compressed air can start to expand and spread out through the primary nozzle and secondary duct passage as soon as it is relieved from the settling chamber. Pressure survey is made using a traverse mechanism mounted with pitot-static tube. Total as well as static pressures along the axial and radial directions of the CFJ were recorded.
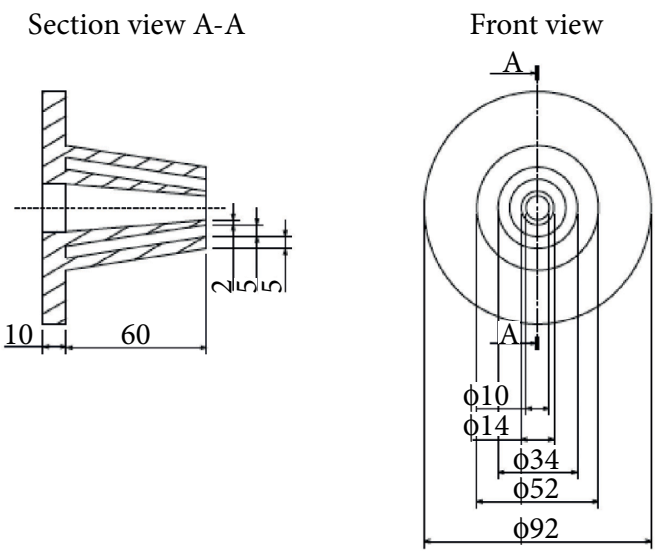

Rear view

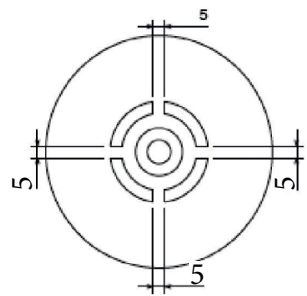

Figure 2. CFJ model with LT $0.2 D_{p}$
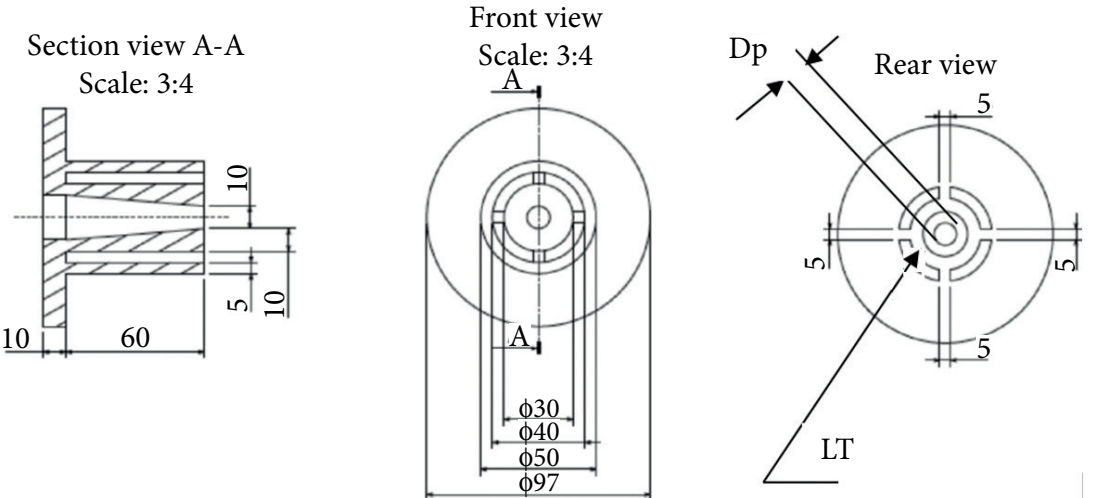

Figure 3. CFJ model with LT $1.0 \mathrm{D}_{\mathrm{p}}$. 

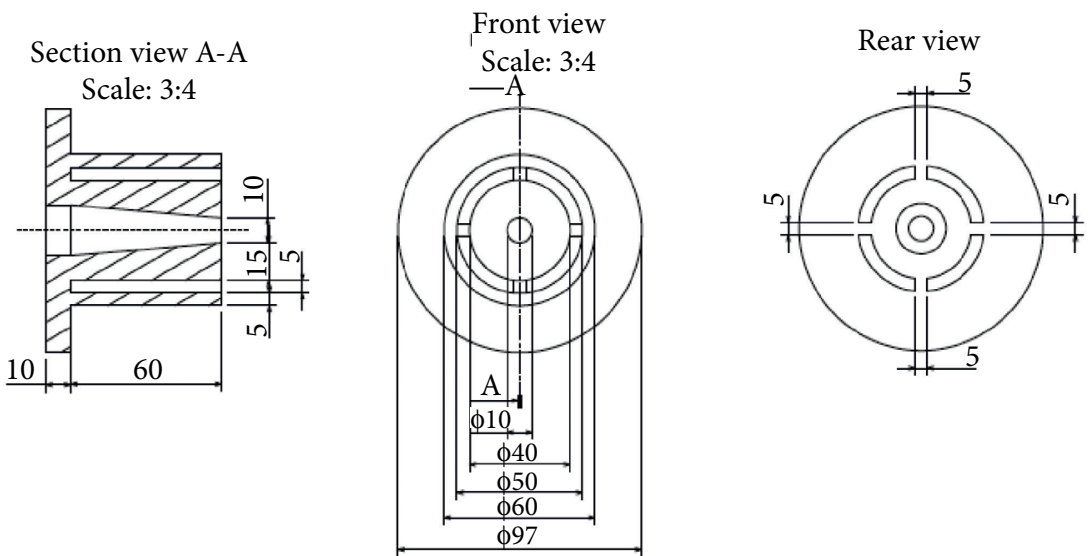

Figure 4. CFJ model with LT 1.5 $D_{p}$.

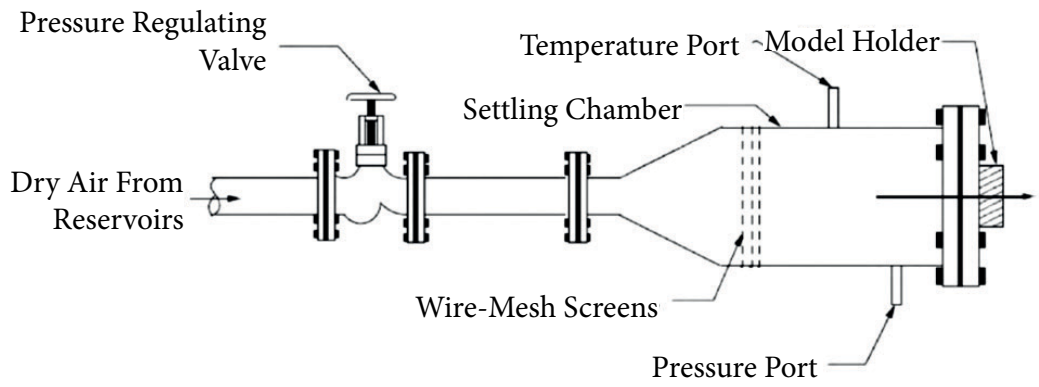

Figure 5. Open jet facility.

In the present investigation, the Reynolds numbers of the jet streams coming out of the nozzle are $0.14 \times 10^{6}, 0.186 \times 10^{6}$, and $0.233 \times 10^{6}$, respectively for the primary jet exit Mach numbers $0.6,0.8$, and 1.0 in the present investigation. Hence, there is not much effect on the Reynolds numbers of the jet by varying lip thickness. Stagnation probe is placed on the axis facing the flow direction to measure the total pressure. Four static probes of $1 \mathrm{~mm}$ diameter each were positioned along the stagnation point to measure the static pressure. Separate static pressure runs were conducted close to the nozzle to observe the effect of sharper gradients and locations of pitot pressure data were correlated (Zaman 2007).

Figure 6 shows the image of the probe used to measure the static and total pressures. The probe used in this research had an internal diameter of $0.4 \mathrm{~mm}$ and a thickness of $0.1 \mathrm{~mm}$. The ratio of the jet cross section area to the projected area of the probe was maintained greater than 64 to neglect the effect of probe blockage. Hence the exit diameter of the coflowing jet nozzle was at least $24 \mathrm{~mm}$. Total pressure was measured by arranging the probe as parallel to the flow. The static pressure was measured by arranging the probe as normal to the flow.

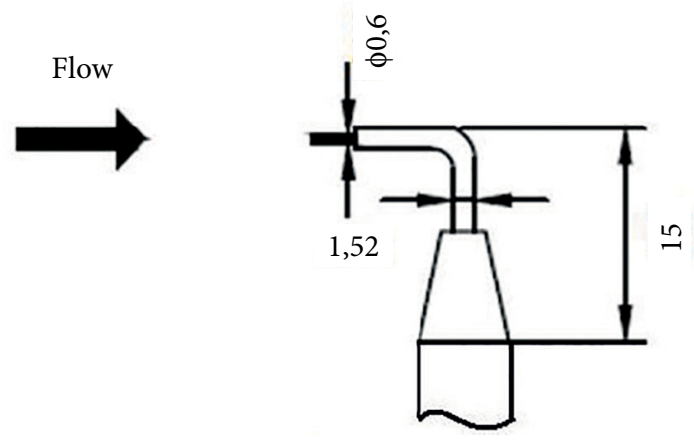

Figure 6. Measure of total and static pressure using probe. 


\section{RESULTS AND DISCUSSION}

To study the effect of Mach number in subsonic coflowing jets, centerline total pressure, centerline static pressure and radial static pressure are analyzed. Three major regions exist in axial total pressure variation such as potential core, characteristic decay and fully developed region are studied. Axial static pressure was assumed constant in previous studies which becomes inappropriate with finite lip thickness and varying Mach number. Thus, axial static pressure is analyzed in the present work.

\section{CENTERLINE TOTAL PRESSURE VARIATION}

Centerline total pressure decay of the primary jet is an authentic measure to quantify the regions of CFJ (Rathakrishnan 2010). Potential core length (PCL) is the axial extent within which stagnation pressure at nozzle exit prevails. The total pressure was plotted along the jet axis, at intervals of $1 \mathrm{~mm}$, up to $20 \mathrm{D}_{\mathrm{p}}$. The jet centerline total pressure decay quantifies jet mixing. This indicates the mixing of primary and secondary jets and combined jet with ambient air. To study the jet spread caused by the CFJ, the total pressure contours were analyzed. In order to evaluate the changes in features of decay, the increase in primary jet exit Mach number, for LT 0.2, 1.0 and $1.5 \mathrm{D}_{\mathrm{p}}$, centerline and pitot pressure variation is plotted against axial distance based on primary jet exit Mach numbers $0.6,0.8$, and 1.0.

Figure 7 shows the centerline pitot pressure decay for LT $0.2 \mathrm{D}_{\mathrm{p}}$ at Mach numbers 1.0, 0.8 and 0.6. Error in the pressure plots in this paper is maintained within $\pm 2 \%$. The PCL for LT $0.2 \mathrm{D}_{\mathrm{p}}$ for Mach 1.0, 0.8 and 0.6 CFJ are X/D $=5$ uniformly for all three Mach numbers. This may be due to the fact that Mach number effect on coflow is insignificant (Srinivasarao et al. 2013). The effect of inclination due to geometrical constraints is found minimal. This is due to the fact that the included angle is $2.86^{\circ}$, which may not have profound effect on primary jet. When the included angle increases significantly, the potential core of the primary jet might be affected because of the impinging nature of the angular jets, which is not so in the present case. The deviation was low along the characteristic decay region. Hence, it can be concluded that the variation in Mach number does not have any significance in LT $0.2 \mathrm{D}_{\mathrm{p}}$ in case of CFJ. The changes in slope along the axis from $\mathrm{X} / \mathrm{D}_{\mathrm{p}}=2$ to 5 is 0 since the potential core ends only up to $\mathrm{X} / \mathrm{D}_{\mathrm{p}}=5$ for Mach numbers 1.0, 0.8 and 0.6 along primary jet exit in the CFJ. Once the flow is established, the flow becomes steady till the secondary jets losses its strength.

When the coflow exist at an angle to the horizontal with respect to CFJ, it is described as angular coflow. In the present study, CFJ exist at the angle of $2.86^{\circ}$ for LT $0.2 \mathrm{D}_{\mathrm{p}}$. However, for the other two cases, i.e., LT $1.0 \mathrm{D}_{\mathrm{p}}$ and LT $1.5 \mathrm{D}_{\mathrm{p}}$, the secondary jet flow parallel to the primary jet at the exit of the nozzle. In other words, the incident angle is $0^{\circ}$ for the CFJ having finite lip thickness.

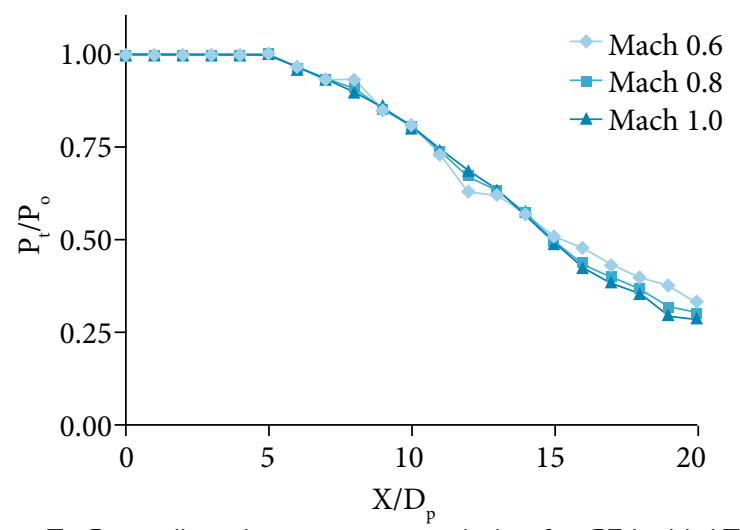

Figure 7. Centerline pitot pressure variation for CFJ with LT $0.2 D_{p}$.

Figure 8 shows the centerline pitot pressure decay for LT $1.0 \mathrm{D}_{\mathrm{p}}$ at primary jet exit Mach numbers $0.6,0.8$, and 1.0. The drop in $\mathrm{P}_{\mathrm{t}} / \mathrm{P}_{\mathrm{o}}$ is indicated as characteristic decay length $(\mathrm{CDL})$ in the plot. Potential core length for CFJ with LT $1.0 \mathrm{D}_{\mathrm{p}}$ for primary jet exit Mach numbers $0.6,0.8$, and 1.0 are $\mathrm{X} / \mathrm{D}_{\mathrm{p}}=2.5,2.0$ and 2.0 respectively. Within the characteristic decay region, due to increase in Mach number, the variation found is very meagre, but unlike LT $0.2 \mathrm{D}_{\mathrm{p}}$, there exists a minor variation in this region. Between $X / D_{p}=2$ and 5 unlike the previous case, due to increased mixing the slope of the curve increases. The variation in 
slope along the axis from $\mathrm{X} / \mathrm{D}_{\mathrm{p}}=2$ to 5 is $0.137,0.148$ and 0.158 for primary jet exit Mach number $1.0,0.8$ and 0.6 . It is found to be zero for CFJ with LT $0.2 \mathrm{D}_{\mathrm{p}}$. Hence the variation in slope increases as LT increases. This is because a dominant wake region that is present in-between primary and secondary jets alters the characteristics in the near field. The variation of slope increases marginally with increase in Mach number for CFJ with LT $1.0 \mathrm{D}_{\mathrm{p}}$.

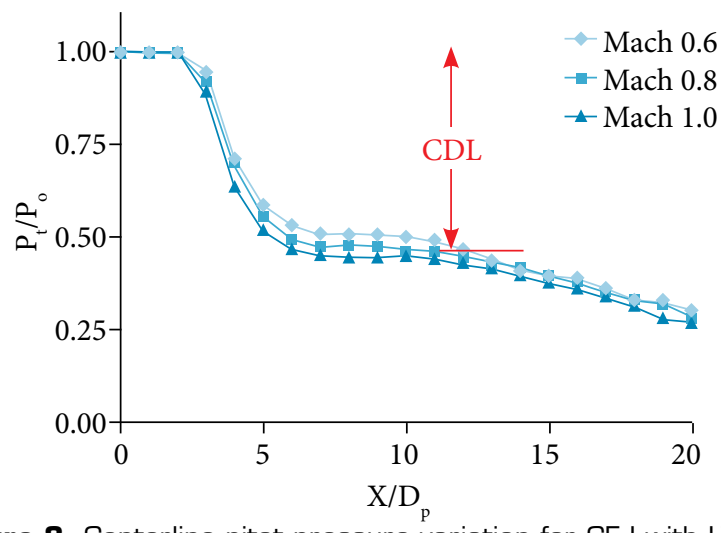

Figure 8. Centerline pitot pressure variation for CFJ with LT 1.O $D_{p}$

Figure 9 shows centerline pitot pressure decay for LT 1.5 $\mathrm{D}_{\mathrm{p}}$ at primary jet exit Mach numbers 1.0, 0.8 and 0.6. The potential core length for CFJ with LT $1.5 \mathrm{D}_{\mathrm{p}}$ at primary jet exit Mach numbers $0.6,0.8$, and 1.0 are $\mathrm{X} / \mathrm{D}_{\mathrm{p}}=1.6,1.6$ and 1.2 respectively. The variation in slope in the near field from $X / D_{p}=2$ to 5 is $0.194,0.195$ for primary jet exit Mach numbers 0.6 and 0.8 .

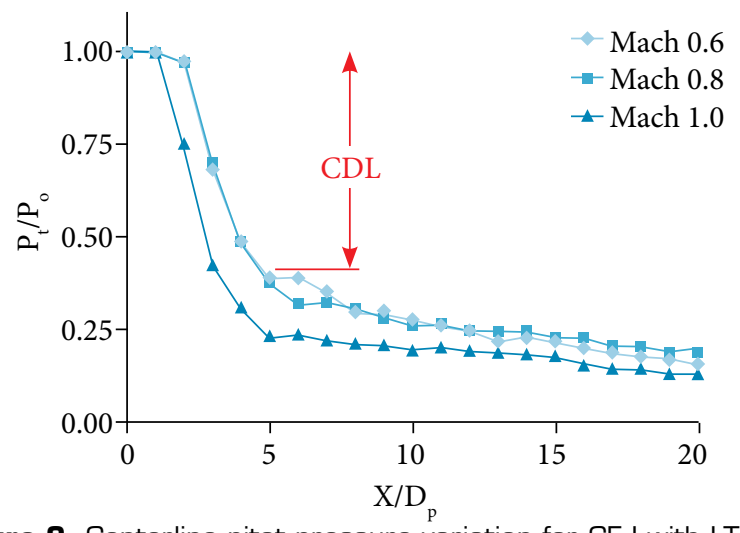

Figure 9. Centerline pitot pressure variation for CFJ with LT 1.5 $D_{p}$.

For primary jet exit Mach number 1.0 the changes in slope along the axis from $\mathrm{X} / \mathrm{D}_{\mathrm{p}}=1$ to 4 is 0.23 . Again, the variation in slope keeps increasing as lip thickness increases. The variation of slope increases marginally with increase in Mach number for CFJ with LT1.5 $\mathrm{D}_{\mathrm{p}}$. The above discussed results are summarized in Table 2.

Table 2. PCL in terms of nozzle exit diameter and its reduction for $L T 0.2 D_{p}, L T 1.0 D_{p}, L T 1.5 D_{p}$ at $M_{p}$ of 0.6 , 0.8 and 1.0 .

\begin{tabular}{|c|c|c|c|c|c|c|}
\hline \multirow{2}{*}{ Type of jet } & \multicolumn{2}{|c|}{ Mach 0.6} & \multicolumn{2}{|c|}{ Mach 0.8} & \multicolumn{2}{|c|}{ Mach 1.0} \\
\hline & PCL $\left(X / D_{p}\right)$ & $\mathbf{D}_{\mathrm{PCL}}$ & PCL $\left[X / D_{p}\right]$ & $\mathbf{D}_{\mathrm{PGL}}$ & $\operatorname{PCL}\left[X / D_{p}\right]$ & $\mathbf{D}_{\mathrm{PCL}}$ \\
\hline LT $0.2 \mathrm{D}_{\mathrm{p}}$ & 5 & --- & 5 & ---- & 5 & --- \\
\hline $\mathrm{LT} 1.0 \mathrm{D}_{\mathrm{p}}$ & 2.5 & $50 \%$ & 2 & $60 \%$ & 2 & $60 \%$ \\
\hline LT $1.5 \mathrm{D}_{\mathrm{p}}$ & 1.6 & $68 \%$ & 1.6 & $68 \%$ & 1.2 & $76 \%$ \\
\hline
\end{tabular}


The flow behavior that lead to improvement in mixing when LT increases can be explained as follows: when LT increases, along the intermediate region, there will be strong mixing between the primary and secondary jets. In this region, extra momentum will be exerted over primary jet by the secondary jet. The increased lip thickness can be used not only to trigger but to control the evolution of organized structures. However, it could increase the turbulence in and around the shear layers. So, it can aid the mixing of the two streams of CFJ (Orlu et al. 2008). This gives more practical importance to such flows. The turbulence affects the characteristics in the initial merging region which lies prior to the intermediate region. The vortices generated by higher lip thickness has larger geometry than that generated by its counterpart having lower lip thickness. This can result in the fast entrainment of secondary flow field and also make the entrainment to readily mix with the composition of primary jet. This can shorten the length of jet by disturbing the PCL of primary jet.

\section{CENTERLINE STATIC PRESSURE VARIATION}

If Mach number of the primary jet increases, then it can cause a considerable variation in static pressure. Hence centerline static pressure variation is plotted against axial distance based on primary jet exit Mach numbers $0.6,0.8$ and 1.0 , for $\mathrm{LT}_{0.2} \mathrm{D}_{\mathrm{p}}, 1.0 \mathrm{D}_{\mathrm{p}}$, and $1.5 \mathrm{D}_{\mathrm{p}}$ as shown in Figs. 9, 10 and 11 respectively. Figure 10 shows the centerline static pressure decay for LT $0.2 \mathrm{D}_{\mathrm{p}}$ at primary jet exit Mach numbers of 1.0, 0.8 and 0.6. Static pressure decreases gradually from the exit of the nozzle and becomes constant after an axial extent as discussed in the previous section. Hence, there is negligible variation in the static pressure irrespective of the Mach numbers. It can be clearly seen from the plot that there is no significant variation found in the near field region. Therefore, the static pressure variation due to the increase in primary jet exit Mach number does not have any noticeable influence on LT 0.2 D of CFJ (Matsumoto et al. 1973).

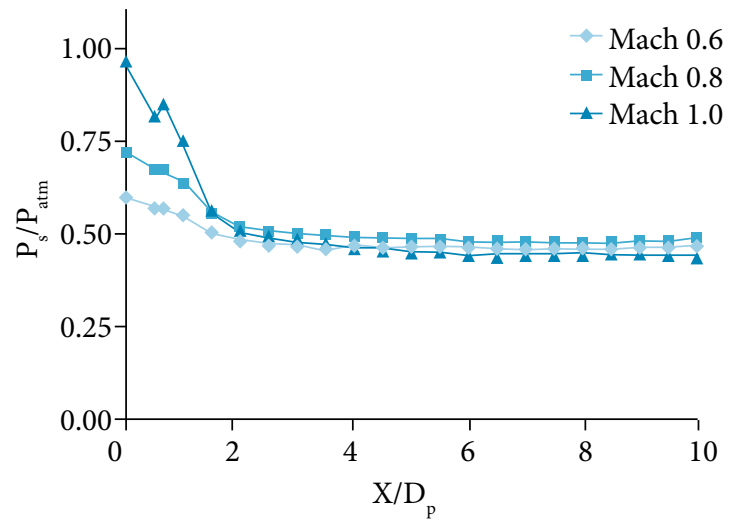

Figure 10. Centerline static pressure variation for CFJ with LT $0.2 D_{p}$.

Figure 11 shows the centerline static pressure decay for CFJ with lip thickness $1.0 \mathrm{D}_{\mathrm{p}}$ at primary jet exit Mach numbers 1.0 , 0.8 and 0.6. In the near field region, as the Mach number increases, rapid variation of static pressure occurs. Hence, there is considerable variation in the static pressure irrespective of the Mach numbers.

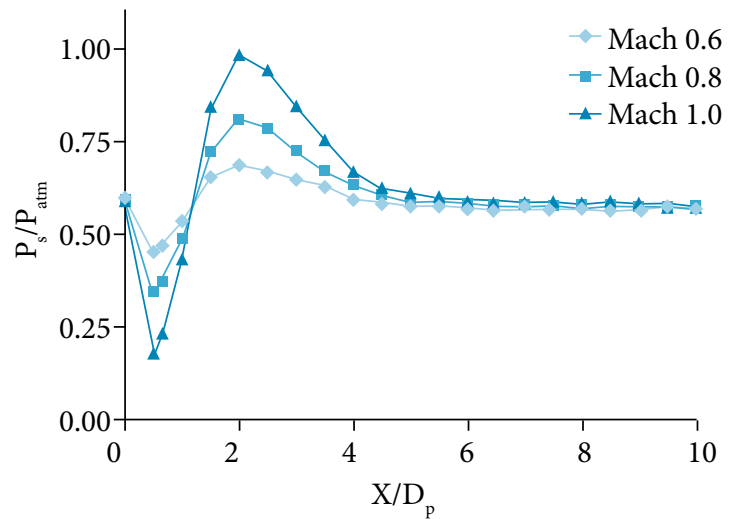

Figure 11. Centerline static pressure variation for CFJ with LT 1.0 $D_{p}$. 
The fall in static pressure below atmospheric pressure $\left(\Delta \mathrm{Ps}_{\text {fall }}\right)$ from nozzle exit to $\mathrm{X} / \mathrm{D}_{\mathrm{p}}=0.5$ is $3 \%, 5.9 \%$ and $10.1 \%$ atm for primary jet exit Mach numbers 1.0, 0.8 and 0.6 respectively. The rise in static pressure above atmospheric pressure $\left(\Delta \mathrm{Ps}_{\text {rise }}\right)$ from $\mathrm{X} / \mathrm{D}_{\mathrm{p}}=0.5$ to 2.0 is $3.3 \%, 6.4 \%$, and $11 \%$ atm for primary jet exit Mach numbers $0.6,0.8$, and 1.0 respectively. The variation in slope of sinusoidal static pressure curve for primary jet exit Mach number 1.0 is more than that of Mach 0.6 and 0.8 . A similar trend is observed for LT $1.5 \mathrm{D}_{\mathrm{p}}$ of CFJ at primary jet exit Mach numbers $0.6,0.8$, and 1.0 as shown in Fig. 12. Hence, there is considerable variation in the static pressure irrespective of the Mach numbers.

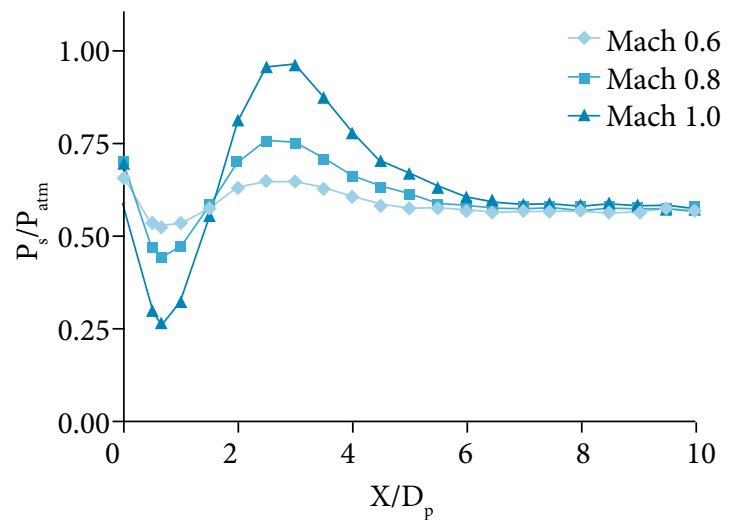

Figure 12. Centerline static pressure variation for CFJ with LT 1.5 $D_{p}$.

The variation of Mach number profoundly influences axial static pressure and it is quantitatively tabulated in Table 3 for primary jet exit Mach numbers $0.6,0.8$ and 1.0 respectively for the three different lip thickness.

Table 3. Comparison of static pressure variation based on primary jet exit Mach number for different lip thickness.

\begin{tabular}{|c|c|c|c|c|c|}
\hline Lip Thickness & Type of Jet & $\mathrm{Ps}_{\min }$ & $\Delta \mathbf{P s}_{\text {fall }}$ & $\mathbf{P s}_{\max }$ & $\Delta \mathrm{Ps}_{\text {rise }}$ \\
\hline \multirow{3}{*}{ LT $0.2 \mathrm{D}_{\mathrm{p}}$} & Mach 0.6 & 3.5 & 2.7 & ---- & ----- \\
\hline & Mach 0.8 & 4.5 & 2.9 & ---- & ---- \\
\hline & Mach 1.0 & 6.0 & 3.2 & ----- & ---- \\
\hline \multirow{3}{*}{$\mathrm{LT} 1.0 \mathrm{D}_{\mathrm{p}}$} & Mach 0.6 & 0.5 & 3.0 & 2.0 & 3.3 \\
\hline & Mach 0.8 & 0.5 & 5.9 & 2.0 & 6.5 \\
\hline & Mach 1.0 & 0.5 & 10.1 & 2.0 & 11.1 \\
\hline \multirow{3}{*}{ LT $1.5 \mathrm{D}_{\mathrm{p}}$} & Mach 0.6 & 0.7 & 1.2 & 2.7 & 2.3 \\
\hline & Mach 0.8 & 0.7 & 3.3 & 2.7 & 5.1 \\
\hline & Mach 1.0 & 0.7 & 7.7 & 2.7 & 10.8 \\
\hline
\end{tabular}

Figure 13 shows comparison of CFJ with LT $1.0 \mathrm{D}_{\mathrm{p}}$ and bypass ratio 6.4 with Matsumoto et al. (1973), where bypass ratio was very high because area ratio was 363 and velocity ratio was 0.54 , giving rise to bypass ratio of 196 . In this study the bypass ratio is comparatively low. Hence, there is noticeable variation in the static pressure irrespective of the Mach numbers. However, in both studies, static pressure rises and lowers along the axis and becomes constant after a far axial extend. 


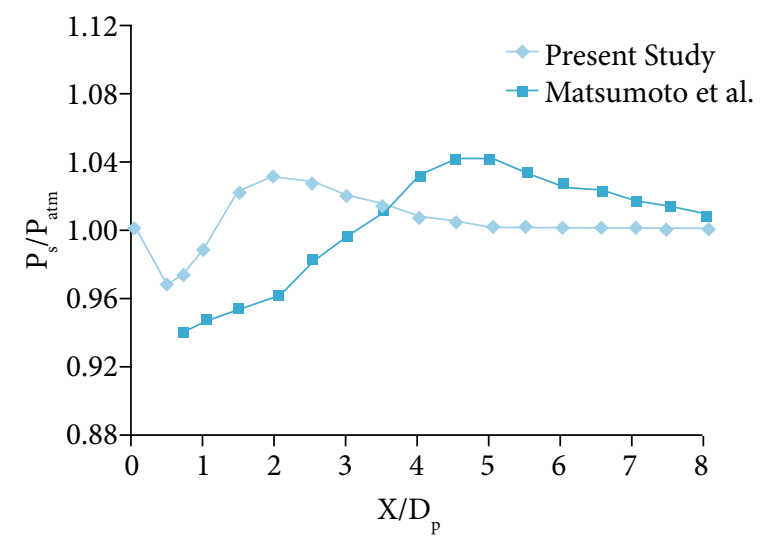

Figure 13. Primary jet axial static pressure comparison between present study and Matsumoto et al. (1973).

\section{RADIAL STATIC PRESSURE VARIATION}

Radial total pressure variation does not vary much with varying Mach number (Shankar et al. 2018). Figure 14 shows the experimental and CFD comparison with varying grids. This reveals that CFD work matches well with experimental work. The CFD contours were obtained from Shankar et al. $(2016 ; 2017 ; 2018)$. The CFD study had good agreement with experimental study by the same author in the previous studies (Shankar et al. 2016;2017; 2018). In radial direction the variation is very minimal i.e., within $\pm 1 \%$. The nondimensionalized static pressure rise along radial direction is shown in Figs. 15 and 17 and corresponding contours are presented in Figs. 16 and 18 respectively.

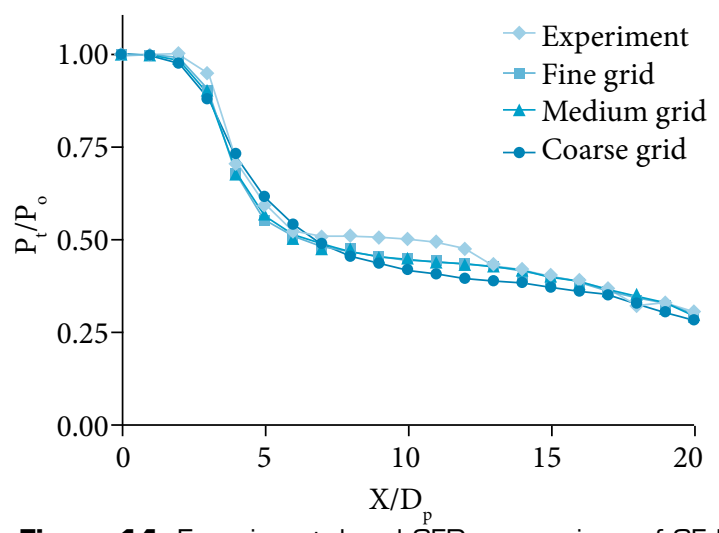

Figure 14. Experimental and CFD comparison of CFJ.

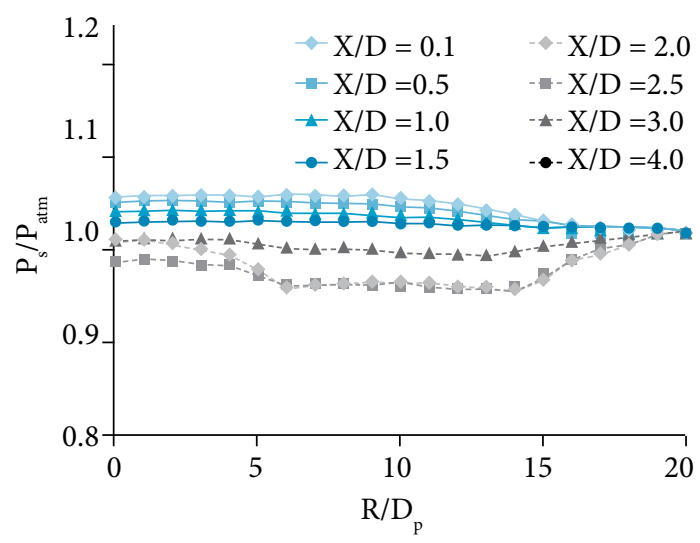

Figure 15. Radial near field static pressure variation for CFJ with $L T 1.0 D_{p}$, at $M_{p} 0.6$. 


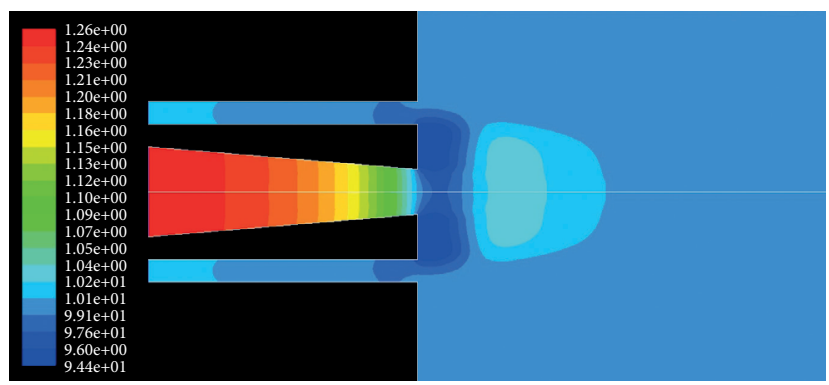

Figure 16. Contours of static pressure for CFJ with $L T 1.0 D_{p}$, at $M_{p}$ 0.6.

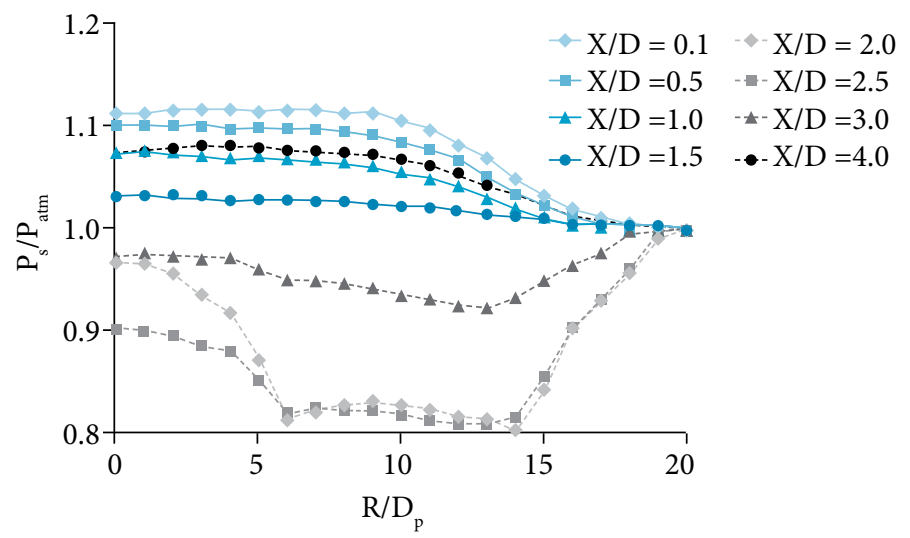

Figure 17. Radial near field static pressure variation for CFJ with $L T 1.0 D_{p}$, at $M_{p}$ 1.0.

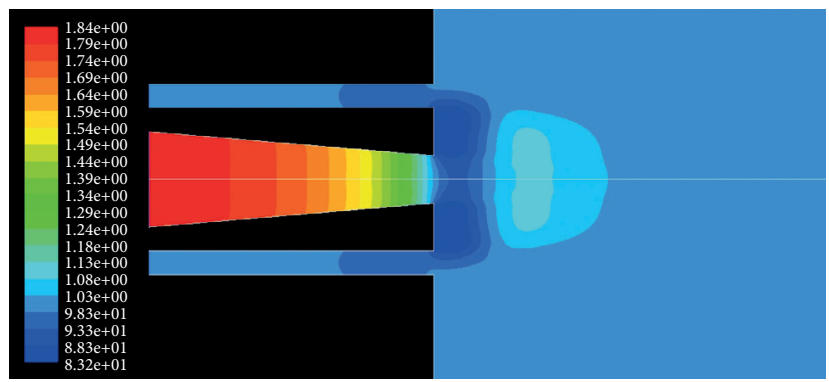

Figure 18. Contours of static pressure for CFJ with LT 1.0 $D_{p}$, at $M_{p} 1.0$.

The static pressure is nondimensionalized with atmospheric pressure. It can be clearly seen that static pressure varies along the radial direction in the wake region. There are more variations in static pressure along radial direction which is due to the flow turbulence. The static pressure variation is noted to increase with the Mach number of the CFJ. On the other hand, the static pressure variation is profound only in the near field region up to an axial station of $\mathrm{X} / \mathrm{D}_{\mathrm{p}}=4.0$, for all coflowing jets analyzed in the present study.

Beyond this axial station the static pressure variation becomes almost negligible. Static pressure contours obtained from numerical simulation confirms the experimental trend. Coflowing jet with relatively high Mach number have significant variation in static pressure particularly at sonic Mach numbers, as seen in Fig. 10 (variation up to $11.1 \%$ ) for lip thickness $1.0 \mathrm{D}_{\mathrm{p}}$.

The reason for static pressure variation along the radial direction can be explained as follows: for large values of lip thickness, huge recirculation zone will be generated just adjacent to the nozzle wall. This is because of intense turbulent mixing of two jets near the nozzle wall, leading to static pressure variation across the region (Matsumoto et al. 1973). Also, when bypass ratio and 
Mach number increase for CFJ with relatively higher values of lip thickness, recirculation zone becomes dominant, and hence static pressure varies profoundly adjacent to the flow field. When bypass ratio and Mach number are found relatively less, only marginal variation in static pressure is observed. Such characteristics can be useful in applications such as fuel air mixing in combustion chamber of aircraft (low sub sonic Mach number), ram jet (Mach number $\leq 0.3$ ) and scramjet (supersonic Mach number), jet mixing in aircraft exhaust, mixing with bluff bodies such as afterburner.

\section{VELOCITY CONTOURS OF COFLOWING JET USING CFD}

In this section velocity contour plots of coflowing jets with different lip thicknesses and bypass ratios are plotted. These contour plots are plotted for Mach number 0.6, since higher values of Mach number do not cause much variation in the jet flow field behavior. When compared to total pressure contours, velocity contours would have a wider jet spread because of the isentropic relation that is followed in converting total pressure and static pressure in terms of Mach number. The values of velocity shown in the contour plots as shown in left hand side of Fig. 19 are in the unit of m/s.

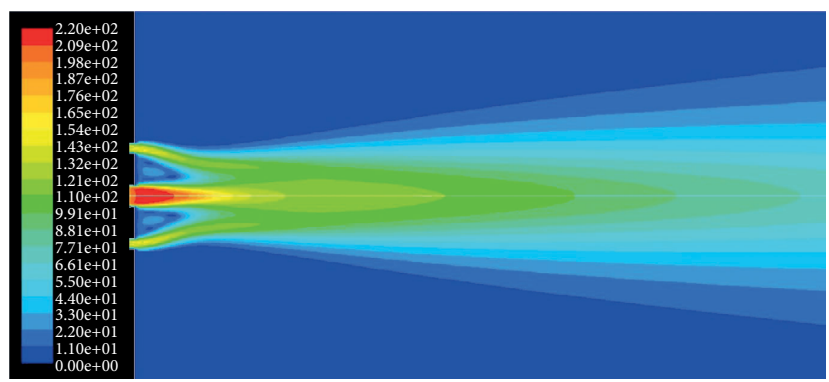

Figure 19. Velocity contour plot for coflowing jets with Lip thickness 1.5 Dp, bypass ratio 6.0 and Mach number 0.6 .

\section{TURBULENCE CONTOURS OF COFLOWING JET USING CFD}

Turbulent viscosity ratio is measured by finding the ratio of eddy viscosity ( $v T)$ to the molecular viscosity (v). Figure 20 shows the ratio of variation of turbulent viscosity in the near field of the coflowing jet. It is observed that, for finite value of lip thickness $\left(1.5 \mathrm{D}_{\mathrm{p}}\right.$ in the present study) substantial value of turbulent intensity occurs behind the nozzle wall.

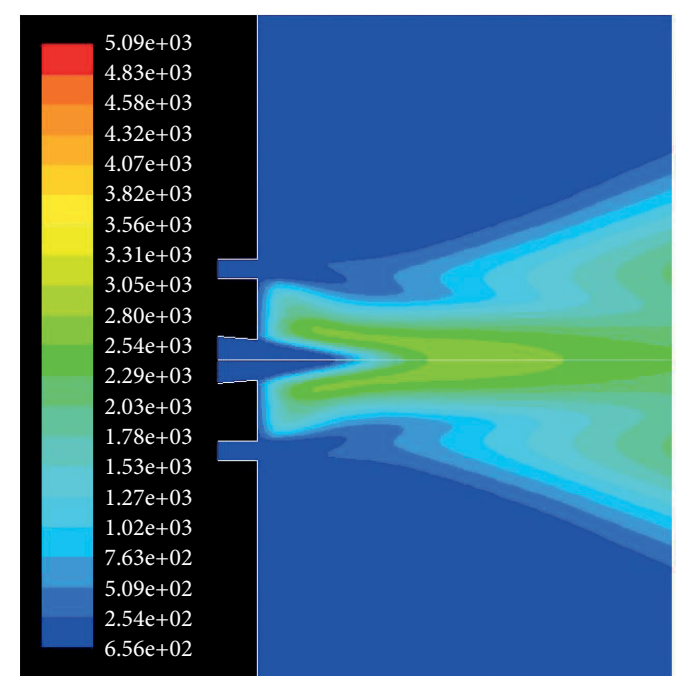

Figure 20. Near field contours of turbulent viscosity ratio for lip thickness $1.5 D_{p}$ primary jet exit Mach number 0.6 and bypass ratio 6.0 . 
The mixing process of primary and secondary jets is being affected by wake behind the nozzle wall and turbulence intensity increases as the lip thickness increases (Shankar et al. 2016;2017; 2018). The turbulence level in the near field is mainly due to the wake formation behind the wall which is responsible for the increase in turbulence intensity with lip thickness. The numerical work carried out in the present study is focused to get an insight on the flow field characteristics and the major research focuses on experimental study.

\section{CONCLUSION}

Coflowing nozzle subjected to subsonic jet flow is studied to correlate the influence of lip thickness and Mach number over the total pressure and static pressure. It is noted that for very small lip thickness, i.e., $0.2 \mathrm{D}_{\mathrm{p}}$ static pressure was maintained constant along the jet. Because of this, the potential core length and decay characteristics did not vary significantly. For this case, changing the Mach number did not show any noticeable variation in the flow characteristic.

Substantial influence of Mach number is noted in the Coflowing jet having finite lip thickness. In other words, the CFJ having considerable lip thickness i.e., $1.0 \mathrm{D}_{\mathrm{p}}$ and $1.5 \mathrm{D}_{\mathrm{p}}$ had noticeable variation in the total pressure and static pressure. Increasing the Mach number results in mixing enhancement along the coflowing jet. However, it shortened the potential core length by $10 \%$ for LT $1.0 \mathrm{D}_{\mathrm{p}}$ and $8 \%$ for $1.5 \mathrm{D}_{\mathrm{p}}$, because of its ability to vary the pressure along the jet. It is observed that along the axis of the jet, static pressure varies from 3\% for Mach 0.6 to $11 \%$ for Mach 1.0. Such incident is novel because the phenomenon does not occur in coflow jet with negligible lip thickness (LT $0.2 \mathrm{D}_{\mathrm{p}}$ ), but occurs for coflowing jets with finite lip thicknesses (LT $1.0 \mathrm{D}_{\mathrm{p}}$ and LT $1.5 \mathrm{D}_{\mathrm{p}}$ ). Increasing the lip thickness promotes wake dominance between primary and secondary jets. This enables better interaction along the length of the jet stream and enhances mixing. Variation in static pressure is profound with finite lip thickness.

\section{ACKNOWLEDGMENTS}

The authors thank Dr. K. Vijayaraja, Head, Department of Aeronautical Engineering, KCG College of Technology, for permitting to conduct experiments. Editors and authors are thankful to Fundação Conrado Wessel for providing the financial support for publishing this article.

\section{AUTHOR'S CONTRIBUTION}

Conceptualization, Naren Shankar R; Methodology, Naren Shankar R; Validation, Naren Shankar R; Writing - Original Draft, Naren Shankar R and Dilip Raja N; Writing - Review and Editing, Naren Shankar R and Dilip Raja N; Supervision, Naren Shankar R and Dilip Raja N.

\section{REFERENCES}

\footnotetext{
Buresti G, Talamelli A, Petagna P (1994) Experimental characterization of the velocity field of a coaxial jet configuration. Exp Therm Fluid Sci. 9(2):135-146. https://doi.org/10.1016/0894-1777(94)90106-6

Lovaraju P, Rathakrishnan E (2011) Experimental studies on coflowing subsonic and sonic jets. Flow Turbul Combust. 87:115-132. https://doi.org/10.1007/s10494-011-9332-5

Matsumoto R, Kimoto K, Tsuchimoto N (1973) A study on double concentric jets: 1st report, experimental results of air-air flow. Bulletin JSME. 16:93:529-540. https://doi.org/10.1299/jsme1958.16.529x

Örlü R, Segalini A, Alfredsson H, Talamelli A (2008) On the passive control of the near-field of coaxial jets by means of vortex shedding. In:
} 
1st international conference on jets, wakes and separated flows. Berlin: Technical University of Berlin.

Papamoschou D (2000) Mixing enhancement using axial flow. In: 38 ${ }^{\text {th }}$ Aerospace Sciences Meeting and Exhibit. Reno: Meeting Paper. 2000-0093. https://doi.org/10.2514/6.2000-93

Rathakrishnan E (2010) Applied Gas Dynamics. New Jersey: John Wiley.

Shankar RN, Thanigaiarasu S, Rathakrishnan E (2016) Numerical characterization of lip thickness on subsonic and correctly expanded sonic coflowing jets. T JPN Soc Aeronaut S. 59(3):134-141. https://doi.org/10.2322/tjsass.59.134

Shankar RN (2017) Effect of lip thickness and bypass ratio on characteristics of co flowing jets. (Doctorate Thesis) Chennai: Anna University. http://hdl.handle.net/10603/180944

Shankar RS, Thanigaiarasu S, Elangovan S, Rathakrishnan E (2018) Coflowing jet control using lip thickness variation. Int J Turbo Jet Eng. https://doi.org/10.1515/tjj-2018-0024

Shankar RN, Bennet SK [2019] Characteristics of a coflowing jet with varying lip thickness and constant bypass ratio. Aircr Eng Aerosp Tec. 91(9):1205-1213. https://doi.org/10.1108/AEAT-01-2019-0007

Shupe R, Zaman K, Papamoschou D (2007) Effect of Wedge-Shaped Deflectors on Flow Fields of Dual-Stream Jets. In: 13th AIAA/ CEAS 2007 aeroacoustics conference (28th AIAA aeroacoustics conference). Rome: Meeting Paper 2007-3659. https://doi. org/10.2514/6.2007-3659

Srinivasarao T, Lovaraju P, Rathakrishnan E (2013) Characteristics of coflow jets from orifices. Int J Turbo Jet Eng. 31(2):141-148. https://doi.org/10.1515/tjj-2013-0040

Thanigaiarasu S, Shankar RN, Rathakrishnan E (2018) Influence of bypass ratio on subsonic and correctly expanded sonic coflowing jets with finite lip thickness. P I Mech Eng G-J Aer. 233[7]:2536-2548. https://doi.org/10.1177/0954410018782511

Zaman KBMQ, Papamoschou D (2000). Study of mixing enhancement observed with a co-annular nozzle configuration. In: $38^{\text {th }}$ Aerospace Sciences Meeting and Exhibit. Reno: Meeting Paper. 2000-0094. https://doi.org/10.2514/6.2000-94

Zaman KBMQ, Dahl MD (2007) Noise and spreading of subsonic coannular jets-comparison with single equivalent jet. AIAA J. 45(11):26612670. https://doi.org/10.2514/1.29441 